\title{
ELS MUSULMANS A CATALUNYA (713-1153). UNA APROXIMACIÓ BIBLIOGRÀFICA
}

\author{
Per \\ PERE BALAÑA I ABADIA
}

Amb ocasió d'un curset de doctorat, l'any acadèmic 1977-1978, vaig aplegar unes dues-centes referències bibliogràfiques (de les quals vaig poder verificar-ne personalment unes cent) relatives a la dominació islàmica a Catalụnya. D'aleshores ençà he anat recollint totes les fitxes que em semblaven adients fins arribar al treball present. En la realització d'aquesta tasca hi ha quatre fites destacables: 1) La col. laboració que, des del 1969, m'ha vinculat al Repertorio de Medievalismo Hispánico, dirigit per Emilio Sáez al C.S.I.C. de Barcelona, del qual han estat publicats els cuatre primers volums (A-Z, 1976-1985), que segurament implicaran l'aparició d'un apèndix i dels índexs necessaris; 2) El fet d'haver participat també en la preparació de la bibliografia sobre les comarques tarragonines editada recentment a cura d'Amadeu-J. Soberanas i Lleó; 3) Les pròpies investigacions, que, girant sempre a l'entorn de la presència musulmana a Catalunya, $m^{\prime}$ han subministrat noves dades i alguns contactes personals que $m$ 'han ajudat a augmentar el cabal de materials interessants; 4) Finalment, l'estímul darrer i un reguitzell d'idees sobre l'organització del recull deriven de l'aparició de Moros y moriscos en el Levante peninsular (Sharq al-Andalus). Introducción Bibliográfica, degut a Míkel de Epalza, Ma Jesús Paternina i Antonio Couto (Alicante, 1983), i de l'apèndix d'aquesta obra inclòs al número 1 de la revista "Sharq al-Andalus. Estudios Árabes" (Alicante, 1984).

El pròleg del llibre esmentat establia tres dimensiones en relació als criteris de selecció seguits. Pel que fa a la dimensió temporal, aquí $m$ 'he limitat voluntàriament al periode de presència "real» dels musulmans a Catalunya excepte quan es tracta de textos sobre les restes materials (arqueológico-artístiques, epigràfiques, numismàtiques, documentals, etc.) o referents a les influències lingüístiques (gramaticals, lèxiques) de la llengua aràbiga sobre la catalana, sovint anomenada tambè valenciana i mallorquina. Des d'una perspectiva espacial, he tingut en compte un concepte ampli del territori del Principat, considerant que al llarg dels diferents períodes cronológics en què hom pot dividir la dominació sarrainna en terres catalanes aquestes han restat sotmeses a les decisions polítiques de centres situats fora dels límits estrictes de la Catalunya actual (com, per exemple, en temps de la "Frontera Superior" o dels reg- 
nes de taifesl. Quant a la dimensió temàtica, bé que la major part d'estudis són de tipus historic, raó per la qual he suprimit l'entrada uhistòria" a l'índex alfabètic de matèries i onomàstic final, crec que hom podrà trobar aquí una munió de treballs sectorials, reflectits en aquest índex. En definitiva, l'aprofitament conjunt de les fitxes bibliogràfiques aplegades a continuació, al meu entendre, podria permetre, en un futur no gaire llunyà, la redacció d'una "Història de la Catalunya islàmica", que encara, malauradament, és per fer.

Respecte a la metodologia seguida, cal donar algunes indicacions breus. El treball consta de dues parts bàsiques. A la primera, una llista alfabètica per autors, cada entrada bibliogràfica va numerada correlativament. Per a un mateix autor les fitxes són ordenades cronológicament. Les remissions internes no duen numeració. He comprovat personalment més d'un setanta per cent de les referències originals; però també incloc algunes fitxes incompletes i $d$ 'altres que corresponen a publicacions encara en premsa; en el camp de la recerca bibliogràfica hom no pot pretendre d'assolir l'exhaustivitat $i$, d'altra banda, a les biblioteques de Barcelona no he pogut trobar aigunes revistes estrangeres. Tanmateix el volum d'informació final pot satisfer els investigadors interessats per la història de Catalunya entre els segles VIII i XII des d'una vessant islàmica. En aquest cas, l'objectiu primordial del treball haurà reeixit. Per tal d'orientar millor el lector, entre parèntesis al començament o al final de nombroses fitxes he afegit algunes especificacions relatives a la forma $o$ al contingut de les publicacions. Aquestes informacions reapareixen a la segona part del treball, un índex alfabètic de matèries i onomàstic que pretén de facilitar la consulta de la llista principal. A l'index he prescindit dels toponims que no pertanyen a Catalunya i dels personatges cronològicament posteriors a l'època considerada. Pertot, tant a la llista com a l'index, he emprat el sistema de transliteració de la llengua àrab proposat per la Gran Enciclopèdia Catalana tot respectant, però, les transcripcions diferents usades als títols dels estudis recollits.

Finalment, una anàlisi minuciosa del repertori bibliograłfic aplegat conduiria a un ventall ampli de conclusions. Aqui només voldria destacar-ne les següents: 1) Les fonts aràbigues de la història de Catalunya són relativament escasses i es troben disperses (reculls biogràfics, cròniques generals sobre al-Andalus, obres de caràcter miscel. lani, etc.l. Per això el descobriment dels perduts "Annals de la Frontera Superior» citats per al- ${ }^{\complement} U d$ dr (vegeu la fitxa $n .^{\circ} 235$ ) suposaria una troballa inapreciable; 2) L'estudi de les restes materials de la cultura islàmiça a Catalunya, especialment mitjançant les excavacions arqueoldgiques, és encara a les beceroles; 3) La major part d'investigadors, desconeixedors de la llengua aràbiga, han treballat basant-se en textos que han esdevingut imprescindibles (per exemple, els que duen els números 323 i 326); 4) Les aportacions més notables procedeixen dels catedràtics de llengua àrab de les universitats de Saragossa i Barcelona (Codera, Millàs, Vernet, etc.); 5) L'àmbit geografic local ha concentrat l'interès dels estudiosos, mentre que una perspectiva més general només ha estat adoptada pels historiadors del fet naciona! català (Salrach, per exemple), per a molts dels quals la dominació islamica a Catalunya tan sols representa, més o menys, un mer "accident» històric.

En el capitol d'agraïments voldria esmentar l'Institut Milà i Fontanals del C.S.I.C. a Barcelona, la biblioteca esplèndida del qual $\mathrm{m}^{\prime}$ ha ajudat moltíssim a fer dia rera dia la feina de recollida i comprovació de dades. I també, no cal dir-ho, la revista "Sharq al-Andalus", que acull a les seves pàgines un estudi realitzat a Barcelona però que difícilment hauria vist la llum en aquesta ciutat. Gràcies!

(Els 539 treballs de la bibliografia es troben, amb aquesta introducció i els indexs, en un llibret separat d'aquesta revista, dintre de la col.lecció SHARO AL-ANDALUS. ESTUDIOS ARABES, Suplementos Bibliográficos, vol. I.) 